\author{
Dominik Bednarek \\ mgr inż. \\ Katedra Mostów i Kolei \\ Wydział Budownictwa Lądowego i Wodnego \\ Politechnika Wrocławska \\ dominik.bednarek@pwr.edu.pl
}

DOI: $10.35117 / \mathrm{A} \_E N G \_17 \_07 \_06$

\title{
Construction methodology of straddle monorail guideway
}

\begin{abstract}
The article describes important issues of prefabrication process of monorail guideway beam, i.e. achieving expected geometry parameters and surface roughness. In the main part, the author characterizes construction method of the most common guideway type focusing on problems connected with transport and assembly of precast beams. Transportation vehicle and tools used for installation of curved beams are described. Afterwards, the author describes problems connected with integration of guideway frame and complex force combination at frame joints. The author finished the description with a short conclusion.
\end{abstract}

Keywords: Monorails; Guide way; Construction methodology; Precast beam

\section{Introduction}

This article is the next in a series devoted to the approximation of monorail systems, poorly known in Poland, which are a kind of unconventional railway with a route leading over the surface. Currently, the most popular type of monorail is the saddle (Fig. 1). The name is associated with the shape of the trolley, which, saddle, i.e. on three sides, includes the rail. The typical construction of such a flyover consists of pile foundations, pillars with a top cap and two girders constituting tracks intended for driving in opposite directions. The shape of the structural elements differs slightly depending on the adopted scheme of static structure, type of vehicle and the city where the line was built. Due to the specific shape of the construction elements, the spar, beam and rail names are used in this article, and the term "flyover" refers to a multi-span bridge structure.

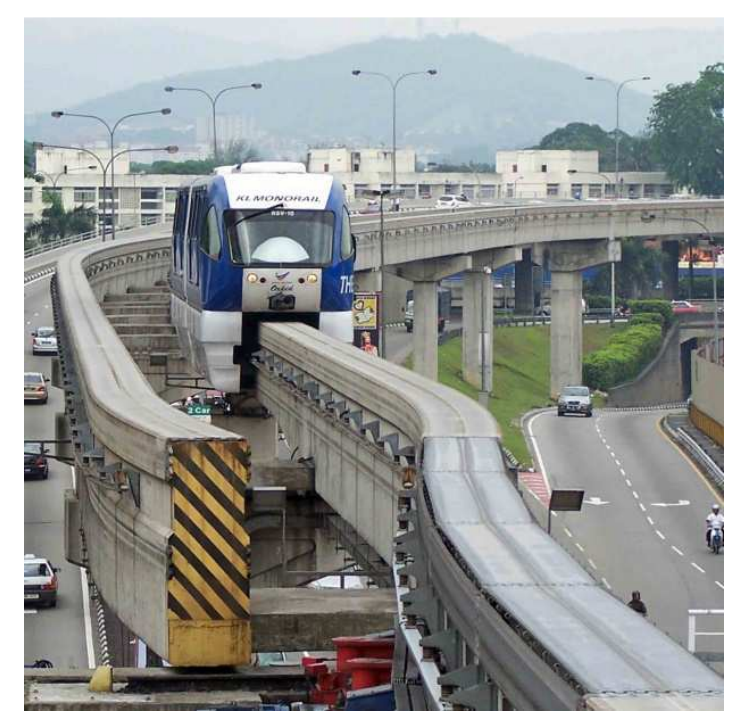

1. Monorail in Kuala Lumpur [9] 
In earlier articles $[2,3,4]$, the general characteristics of monorail were presented. The first of these publications addresses issues related to security systems used on monorail lines as well as methods of evacuation. In [3], the advantages and disadvantages of monorail systems are presented. The construction elements of the flyover have been described in detail in [2], just like the selected types of monorail trains.

This publication will be a description of a typical method of erecting a monorail railway overpasses. The most common type of structure consists of foundations and reinforced concrete pillars and prefabricated rails. The precise performance of rolling surfaces is essential for the operational requirements. No additional finishing layers are made on the girders, which may have been a correction element for inaccuracies created in the prefabrication plant.

Detailed planning of prefabrication and assembly enables a significant acceleration of the construction process. Moreover, it is necessary due to the complex geometry of the route. Importantly, shortening the time of erection of the line results in a reduction of construction costs and reduction of nuisances related to the closure of streets for the duration of the works.

The article describes important aspects of the prefabrication process of the flyover girders. Specific requirements related to the expected accuracy of the rail geometry and the corresponding texture of the rolling surface were indicated. Then, the typical stages of the construction of flyovers forming the monorail line are described. Particular attention was paid to problems related to the transport and assembly of rails. The character of the effort of beams during placing them on supports was discussed, the vehicle used for transporting beams and the handles allowing the installation of curved girders in the plan. In addition, the stress level in the frame nodes is presented and the problems associated with the performance of girder bracing are described. The article was concluded with a short summary.

\section{Prefabrication of girders}

As already mentioned, no surface is laid on the girders of the monorail. The concrete surfaces of the beam are at the same time rolling surfaces for the train wheels. All unevenness on these surfaces are a factor having a direct impact on the wear of rails and translate into wear of tire tires or train vibrations that impair driving comfort. Therefore, in order to maintain the expected accuracy, the production process is entirely carried out at the prefabrication plant. Complicated course of the route, i.e. arched sections in the plan and profile, as well as transients along with cant and differences in beam spans make almost every girders unique. In order to determine the expected beam geometry, a three-dimensional model of the flyover is performed showing the detailed course of the route and the dimensions of the beams (Fig. 2). Then a series of workshop drawings is made, which illustrate in detail the geometry of the beam, including its shape in the plan and profile as well as changes in the section height of the rail along its length, the shape of the relief insert, the soft reinforcement system and the course of the channels for the pre-stressing cables. 


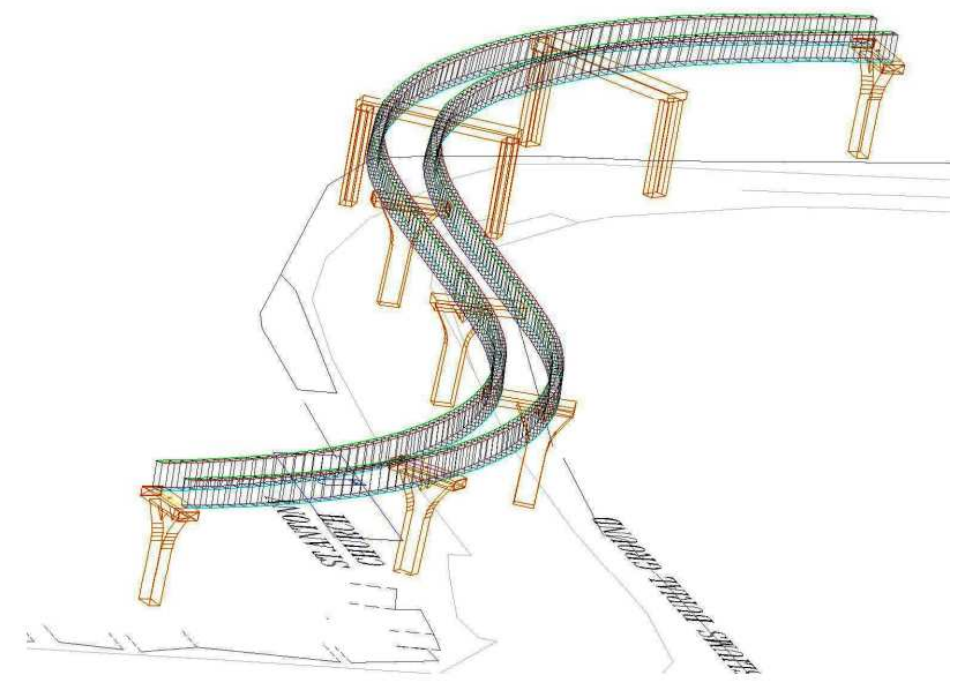

2. Three-dimensional flyover model [14]

The production process takes place in six stages: preparation of reinforcement, shaping of formwork, laying of concrete mix, care of concrete, introduction of pre-stressing cables and preliminary compression and transport to the warehouse. Finally, the second compression and injection is performed. First, the reinforcement basket is prepared, the compression cables are placed inside with the steel anchor blocks and the lightweight insole relieving the beam (Fig. 3). In the case of some systems, at this stage, the beams are fixed to the reinforcement of the beam bearings. The next step is the preparation of an external formwork. A significant difficulty in this and the previous production phase is the uniqueness of each of the beams. The formwork used to make the beams allows for any geometrical shaping of the beam (Fig. 4), including the change of the beam height along its length.

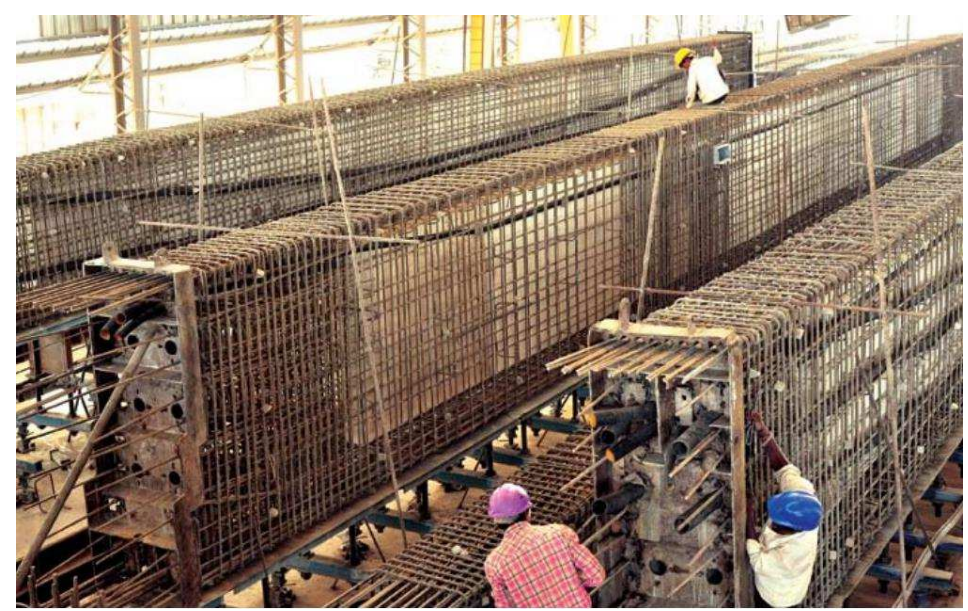

3. Preparation of reinforcement [12] 

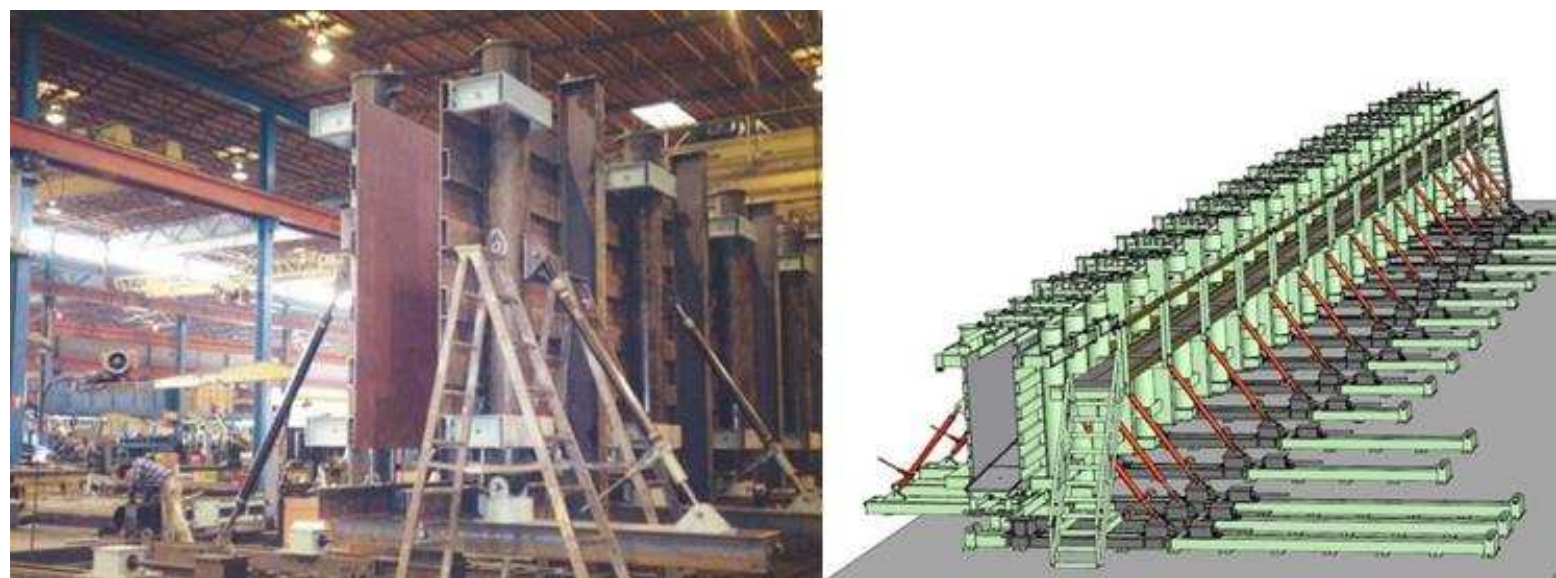

4. Formwork girders

After placing the reinforcement inside the mold and rectifying the formwork, concreting takes place using concrete with compressive strength of min. $45 \mathrm{MPa}$. In order to accelerate the increase in strength, concrete infusions are used. Two days after the concrete mixture is laid, the first pre-compression is performed, after which the girder is transported to the storage yard. The second compression is carried out after 14 days from concreting. The force in the pre-stressing cables obtained at this stage is provided for transferring the loads acting on the beam during transport and assembly. Both after the first and second compression in the prefabrication plant, the girder lifts are inspected due to the cable tension, and in the earlier stages the geometry of the formwork and the prefabricated beam is controlled [15], [6]. The necessary degree of precision can be demonstrated by the requirements set during the prefabrication of girders in the Sao Paulo line, up to a $6 \mathrm{~mm}$ elevation due to compression was allowed. The width of the beam could not deviate from the designed more than $1.6 \mathrm{~mm}$. The allowable divergence of the cross-sectional angles of the beam from the designed is limited to $0.22 \%$. Simple girders were made with a deviation not exceeding $1.5 \mathrm{~mm}$ by $1.5 \mathrm{~m}[1]$.

Another important aspect in the production of rails is to obtain the correct texture of concrete on rolling surfaces. The mixture used must ensure optimal wheel adhesion. Due to the lack of a universal recipe of concrete, the proper mix used on the Mumbai line was achieved by trial and error. The upper surface of the girder was additionally roughened with a hard bristled brush [6]. In addition, the concrete mix must have high abrasion resistance and allow for a good compaction of the concrete. All kinds of air voids and areas are poorly compacted in the case of rails [1].

Experience from more than 30 years of operation in Disney's Florida park shows that monorail beams show only minor damage. It was observed that concrete was detached on the lower surface around the concrete spacers used for concreting the girder. Similar damage occurred around the places, where the mounting brackets were located. Significant damage was the clash of the upper surface of the beam at places, where trains regularly braked or accelerated. All these defects are repaired using PCC (polymer modified concrete) mortars with high strength [13].

\section{The construction technology of the flyover}

The process of building a monorail railway flyover is analogous to that of other bridge structures built from prefabricated beams. The construction stages are shown in Figure 5. The requirements related to the operation of the line mean that special precision of the construction must be ensured during the erection process. This is particularly difficult while striving to complete construction as soon as possible. Any delays associated with the creation 
of a new line translate into additional nuisance for the residents of the city and an increase in construction costs. That is why, it is important to precisely plan the process, both the schedule of the construction and installation industry, as well as planning changes in communication in the city. The goal is to implement the construction with minimal impact on the traffic of cars and existing public transport. An additional problem in the implementation of the investment is the location of the girder prefabrication plant. This object is generally erected for the needs of the construction of the line. The prefabrication plant with the required production capacity requires a space of about 1.5 ha, on which the prefabrication and care stands of the beams and the storage yard must be located. Such a facility is possible to implement only in the suburbs, which extends and complicates the transport of girders to the destination.

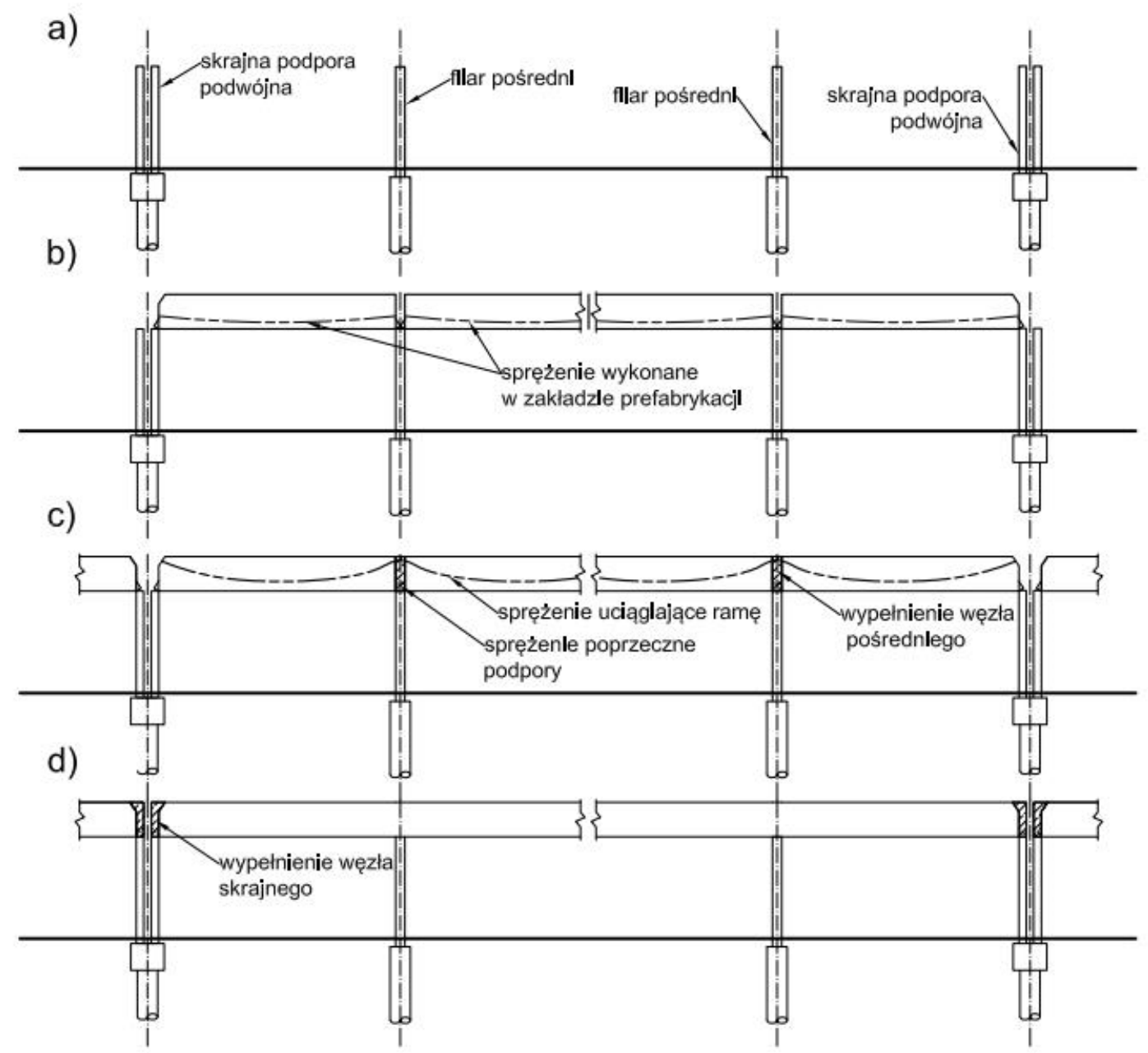

5. Diagram of construction stages

The first stage of construction consists in making foundations and pillars of the flyover. Foundation piles are most often implemented as drilled large-diameter piles. This technology is the least onerous for residents and does not have a negative impact on the surrounding development. With the implementation of the piles, the underground infrastructure is being rebuilt, which is in conflict with the new foundation. Elements of the foundation, as well as the pillars are made of reinforced concrete with high strength. In order to speed up the implementation, prefabrication of reinforcement baskets is used. Column concreting takes place in several stages due to its dimensions, as well as variable geometry. A 
break in concreting is made on the pillar of the pillar in order to later connect the supports with the girders (Figure 6) or to make underbearing blows.

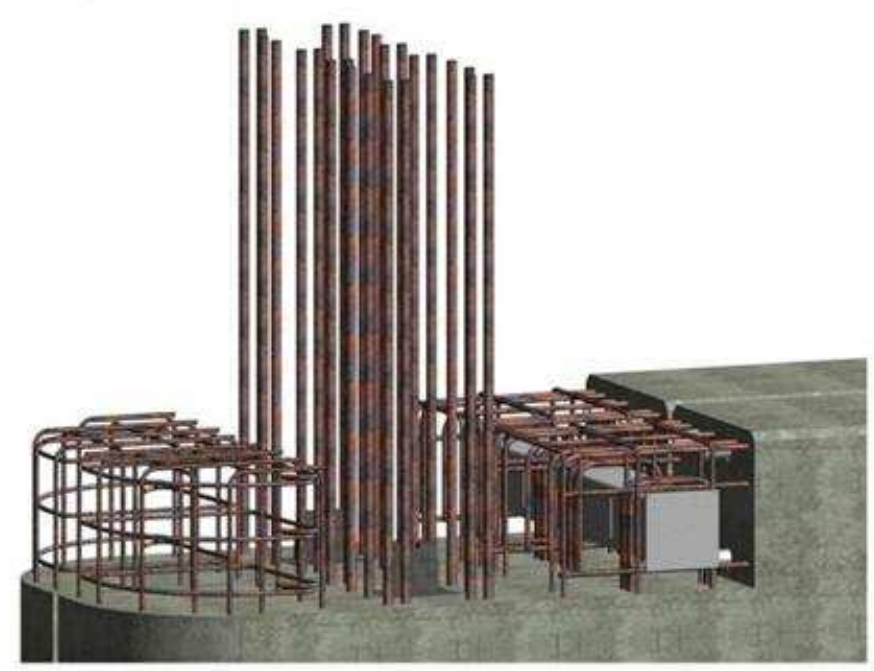

6. Visualization of the work gap in the front of the pillar of the complex system [5]

Assembly of the girders begins after obtaining adequate strength of concrete in the cap supports (Fig. 5b). The transport of beams and placing them at the destination takes place at night. The length of transported elements reaches up to $35 \mathrm{~m}$ and their weight up to 85 tons, which makes such transport to be non-normative. An additional difficulty during transport is different beam geometry every time. A tractor unit and semi-trailer with a structure enabling division into two parts are used for the carriage of beams (Figure 7). Each of them moves on four axes, and each axle is equipped with eight wheels. The way of fixing the wheels to the trailer allows for even distribution of pressure on the wheels regardless of their mutual position. In addition, the rotation of each axle is ensured, which significantly improves the manoeuvrability of the vehicle.

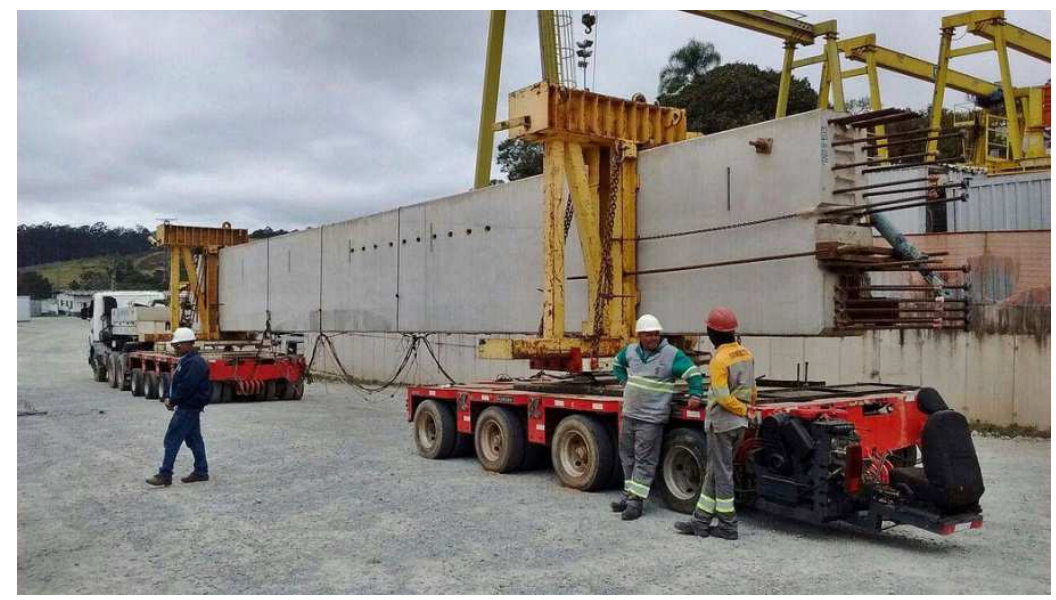

7. Spool transporting semi-trailer [10] 
During the transport and assembly, the beam is stabilized transversely with the use of struts connected to the temporary steel clamp of the beam (Figure 7). It stabilizes the load and limits the dynamic loads associated with vibrations of the moving vehicle that are transferred to the beam. The transfer of the girder to the support is carried out using two cranes. The position of the fixing brackets along the length of the beam is important during the transfer. On the one hand, one must counteract the possibility of the girder slipping out of the handles, on the other hand, too large displacement of the handles towards the middle of the beam changes the nature of its effort. The weight of the free ends of the beam in the extreme case could cause too high tensile stresses on the upper surface of the beam in the area of the mounting brackets and as a consequence its scratching.

Another problem is the transfer of curved beams. With the point of support at the ends of the beam, the self-weight action causes twisting. In order to better balance the beam and thereby reduce the twisting effect, the location of the suspension of the holder towards the centre of gravity of the beam moves (Fig. 8). Based on the analysis of the beam's condition during assembly, the place where the handles should be placed [6] is determined.

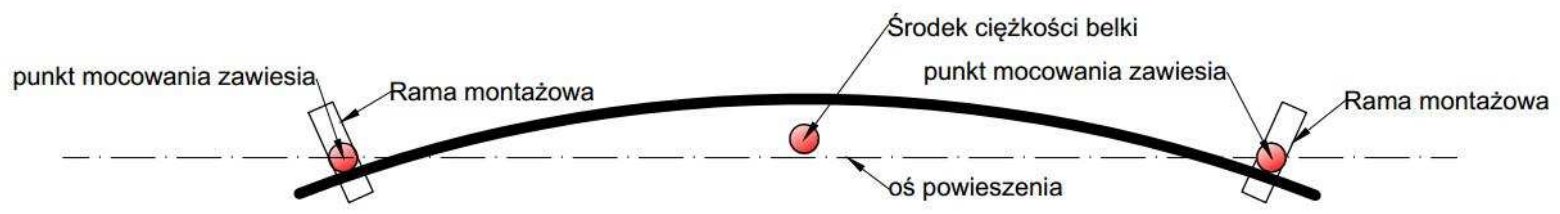

8. Diagram showing the method of balancing a curved beam during transfer

The final position of the beam on the support is stabilized by means of steel struts fixed in the pillar (Fig. 9). After installation, the position of the girder in the plan and the cant are checked. Permissible displacement of the beam from the one assumed in the project is a maximum of $12 \mathrm{~mm}$ on the route, and only $3 \mathrm{~mm}$ in the area of stations and turnouts, while the deviation of the superelevation cannot exceed $0.5 \%$ [1]. Larger differences could cause excessive tire wear.

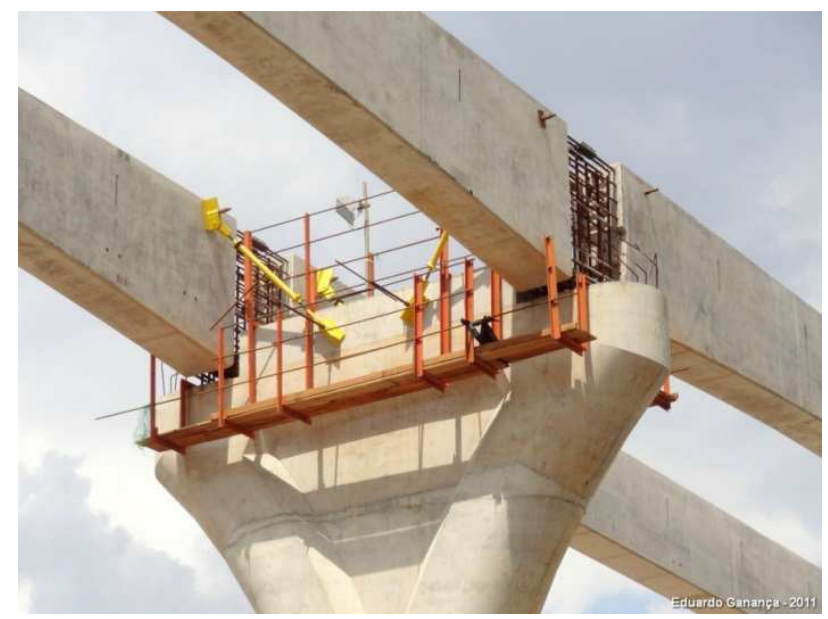

9. Stabilization of girders after assembly on a support [8]

In the case of a line consisting of a number of free-supporting beams, after setting the girders at the final destination, the equipment is installed, i.e. expansion joints, cable trays and 
other power elements and possible evacuation platforms. However, if the line is designed as a continuous system, we go to work related to the assembly of the structure. Cable ties are introduced to previously made cable ducts, which are to connect neighbouring elements and at the same time increase their load capacity (Fig. 5c). The additional compression made in this way is to provide the load capacity required during operation. After carrying out the tendons, the reinforcing bars are made from neighbouring beams and reinforcement of the support. This is necessary due to the complicated nature of the load of supporting nodes. The support nodes are responsible for transferring the loads from the beams to the support, and these loads cause the reaction of the nodes acting on the directions of all degrees of freedom. After concreting the knot and obtaining the proper compressive strength of the concrete, the connecting rods are compressed. This order aims to improve the connection between the prefabricated beam and the freshly made concrete node. This connection is frictional. Compression stress due to compression improves the shear capacity of the connection. For the same purpose, beams have been used, the faces of which have recesses (Fig. 10). In addition to the compression along the beams, the support is transversely stressed (Fig. 5c) [6].

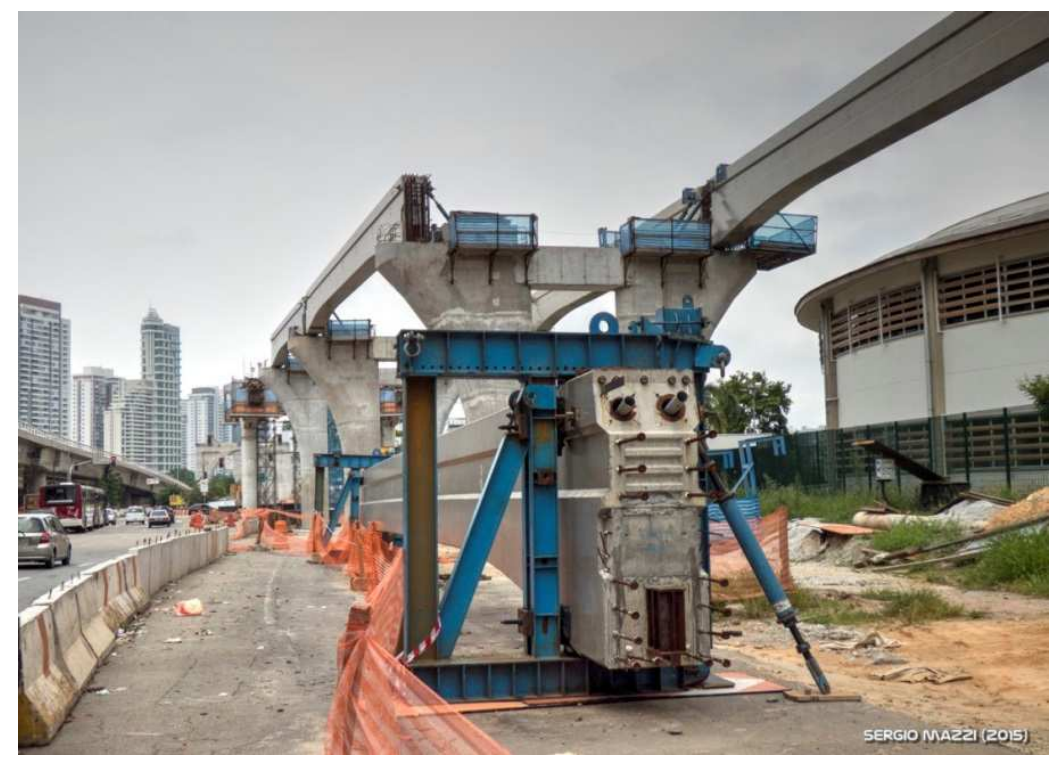

10. End face of the beam [11]

The construction of the flyover carrying structure ends with the filling of the outermost nodes of the frame and the execution of expansion joints (Fig. 5d). The design and implementation of end nodes is associated with problems that do not occur in intermediate nodes. The own weight of neighbouring spans evenly loads the intermediate supports. In the extreme span, the resultant weight of the girders operates on a considerable eccentricity and causes the rotation of the extreme supporting node. The smaller area of the girder support on the extreme support results in less stiffness of the knot, which further intensifies this effect. Moreover, the load-bearing capacity of the connection between the concrete made in-situ and the concrete of the prefabricated girder at the extreme node is much smaller. This is due to the difference in the value of the compressive force acting on the contact surface. The prestressing cables force the girders of adjacent spans to the concrete of the intermediate node. The connection of the extreme node of the frame is not additionally compressed because the compression cables are anchored on the face of the girder (see Fig. 11). During the concreting of the beam connections, a fragment of the upper girdle of the support is also concreted [7]. 


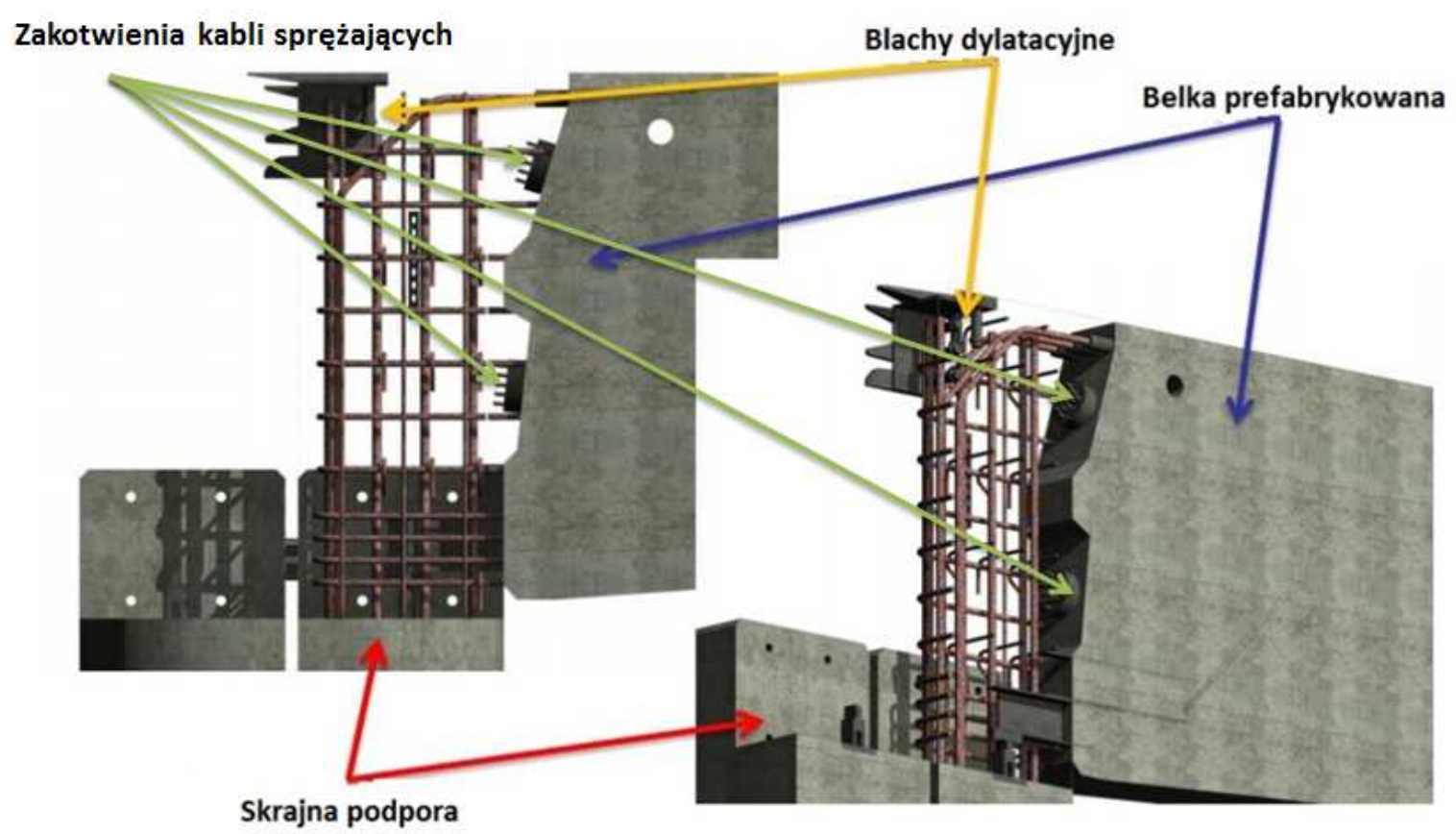

11. Visualization of the reinforcement of the outermost node of the frame [5]

After finishing the final nodes and laterally compressing the extreme supports, beam stabilizing elements are removed and the equipment is moved to assembly. Expansion joints are installed which allows the wheel to run smoothly on each of the rolling surfaces. Depending on the type of monorail system and local safety requirements, assembly of evacuation platforms is carried out. Cable trays are installed and necessary telemechanical installations are installed to supply the train.

\section{Summary}

The construction of the monorail railway line is a process largely similar to the implementation of other bridge constructions. The article presents the course of erection of the most common type of flyover, starting from the preparation of prefabricated girders, and ending with the assembly of equipment elements. Particular attention has been paid to the essential aspects of the production and assembly of concrete rails.

The publication describes the most important problems of the prefabrication process of concrete girders, i.e. obtaining the right beam geometry and choosing the right concrete mix. In addition, the vehicle used to transport the beams is described, as well as the way in which the beams are placed on the pillars. Attention was paid to the difficulties associated with the assembly of curved beams in the plan, and then the process of constructing the structure was described, emphasizing the way of constructing connections in the nodes over the pillars.

As a result, it can be concluded that proper planning and preparation of the monorail line construction process is necessary due to its complexity. The planned routes have a complicated course both in the plan and the profile, which results in the fact that almost every fragment is unique.

\section{Source materials}

[1] Banchik C., Achieving construction tolerances for rubber tire mounted monorail concrete beams, Monorailex 2013 Conference Reader, Daegu, 2013. 
[2] Bednarek D., Bryja D., Układy konstrukcyjne kolei jednoszynowych, Przegląd Komunikacyjny, 2015, nr. 6, s. 28-32.

[3] Bednarek D., BryjaD., Jednoszynowe koleje nadziemne jako skuteczny środek transportu publicznego $w$ duzych aglomeracjach miejskich, Projektowanie, budowa $\mathrm{i}$ utrzymanie infrastruktury w transporcie szynowym, Infraszyn 2015, Zakopane, 2015, s. $15-28$.

[4] Bednarek D., Gisterek I., Bezpieczeństwo kolei jednoszynowych, Przegląd Komunikacyjny, 2015, nr 9, s. 87-89.

[5] Beier M., Banchik C., Associação Brasileira de Engenharia e Consultoria Estrutural, http://www.abece.com.br/web/download/pdf/enece2011/Carlos\%20Banchik\%20\%20Power\%20point\%20Enece\%202011.pdf, 30.08.2016.

[6] Bhoot M., Kumar V., Design and construction of Monorail Guideway Beams, Sympoosium of Indian Institute of Bridge Engineers, Bengaluru, maj 2011, s. 1-14.

[7] Bhoot M.,Abrea E., Integral frames for Mumbai Monorail Guideway, Journal of Inian Institute of Structural Engineers, marzec 2012.

[8] GanançaE.,http://www.skyscrapercity.com/showpost.php?p=86903640\&postcount=193 $1,30.08 .2016$.

[9] http://www.rickmann-uk.com/wp-content/uploads/Monorail.jpg, 25.03.2017.

[10] http://www.skyscrapercity.com/showpost.php?p=135008167\&postcount=3817, 30.08.2016.

[11] Mazzi S., www.skyscrapercity.com/showpost.php?p=130825869\&postcount=3703, 30.08.2016.

[12] Nerurkar A. R., Srinath M., Mumbai Monorail India's first monorail corridor, ECC CONCORD, 2015, nr 1, s. 3-12.

[13] Shmerling R. Z., Structural Condition Assessment Of Prestressed Concrete Transit Guideways, Department of Civil and Environmental Engineering in the College of Engineering and Computer Science at the University of Central Florida, Orlando, Masters Thesis, 2015.

[14] Worthy Builders Sdn Bhd., Construction Metodology of Monorail Guideway Beams, https://pl.scribd.com/document/258456229/Construction-Methodology-of-MonorailGuideway-Beams, 30.08.2016.

[15] Yong-Mo A., Daegu metropolitan line 3 monorail is built like this, Monorailex 2013 Conference Reader, Daegu, 2013. 